\title{
Síntese e \\ Caracterização do \\ N-Lauroil Quitosana
}

\author{
Danillo Alencar e Silva, Aline Fernandes Barcelos, Camilla \\ Lourenço Vieira \& Roberta Signini
}

O N-Lauroil Quitosana é um derivado de quitosana e foi obtido pela reação entre quitosana e cloreto de lauroila. O N-Lauroil Quitosana foi purificado e caracterizado por espectroscopia de infravermelho e por análise térmica.

Palavra Chave: Quitosana: N-Lauroil Quitosana: Caracterização.

The N-Lauroyl chitosan synthesized is a derivative of chitosan produced through the reaction between the chitosan and Lauroyl chloride. The N-Lauroyl chitosan was purified and characterized by infrared spectroscopy and termal behavior.

Keywords: Chitosan; N-lauroyl chitosan: Characterization. 


\section{Introdução}

A quitosana é obtida a partir da desacetilação da quitina, um dos polissacarídeos mais abundantes da natureza e constituinte do exoesqueleto de crustáceos, além de outras fontes (ROBERTS, 1992).

A quitosana é um biopolímero que possui a presença de grupos reativos em sua estrutura, tais como $\mathrm{NH}_{2}$ e $\mathrm{OH}$, possibilita diversas modificações químicas, responsáveis por mudanças nas propriedades físico-químicas do polímero e expansão dos seus campos de aplicação (RINAUDO,2009).

Assim, este trabalho teve como objetivo sintetizar um derivado de quitosana, o N-Lauroil Quitosana, e caracterizálo por meio da espectroscopia de infravermelho e analise termogravimetrica.

\section{Metodologia}

\section{OBTENÇÃO E PURIFICAÇÃO DO N-LAUROIL QUITOSANA (VIEIRA, 2016)}

Para obtenção do N-lauroil quitosana foram suspensos $15 \mathrm{~g}$ de quitosana em levada à agitação mecânica durante 18 horas. Posteriormente ajustou-se o $\mathrm{pH}$ até atingir $\mathrm{pH}$ 6,8-7,0. Adicionou-se lentamente 7,5 mL de cloreto de lauroíla e o $\mathrm{pH}$ foi ajustado novamente. Em seguida a amostra sofreu agitação mecânica por 6 horas. Após esse tempo foi adicionado etanol até a precipitação completa. O precipitado foi filtrado e lavado com etanol e acetona em seguida seco a temperatura ambiente.

Para ocorrer a total extração do ácido formado, o filtrado permaneceu em refluxo por $48 \mathrm{~h}$ em metanol. Após o término da extração o resíduo sólido foi seco a temperatura ambiente e depois triturado no tamanho adequado.

\section{CARACTERIZAÇÃO DO N-LAUROIL QUITOSANA}

A caracterização das amostras foi realizada utilizando o Espectrômetro de Infravermelho para a identificação dos grupos funcionais presentes, esta análise foi realizada com quitosana e N-Lauroil Quitosana. Também foi realizado o estudo do comportamento térmico da amostra por medidas de TGA.
Espectroscopia de Infravermelho com transformada de Fourier (FTIR): Uma pequena parte da amostra foram secas em estufa a vácuo a $60^{\circ} \mathrm{C}$ por $12 \mathrm{~h}$ e posteriormente foram pulverizadas com $\mathrm{KBr}$. Após foi realizado a a análise no espectrofotômetro de infravermelho Perkin-Elmer modelo Spectrum Frontier FTIR/NIR, na região espectral de 4000 a $400 \mathrm{~cm}^{-1}$.

Análise Termogravimetrica (TGA): A estabilidade térmica das amostras foram realizadas em aparelho P1TGA da marca Perkim Elmer. Para a análise foi empregado atmosfera dinâmica de $\mathrm{N}_{2}$ a uma vazão de $20 \mathrm{~mL} \mathrm{~min}^{-1}$. O aquecimento ocorreu a uma taxa de $10^{\circ} \mathrm{C} \mathrm{min}^{-1}$, partindo de uma temperatura de $25^{\circ}$ até $800^{\circ} \mathrm{C}$.

\section{Resultados e Discussão}

No espectro do N-lauroil quitosana houve formação de picos mais evidentes quando comparados com o espectro da quitosana (Figura 1).

Observa-se que em $2926 \mathrm{~cm}^{-1}$ o pico acentua-se no espectro do N-Lauroil Quitosana caracterizando um estiramento dos grupos $\mathrm{C}-\mathrm{H}$; em $1660 \mathrm{~cm}^{-1} \mathrm{o}$ pico se torna mais evidente e se refere ao estiramento $\mathrm{C}=\mathrm{O}$; em $1550 \mathrm{~cm}^{-1}$ nota-se a aparição de um pico médio que corresponde a deformação angular do $\mathrm{N}-\mathrm{H}$ do grupo amida; em $1380 \mathrm{~cm}^{-1}$ torna-se mais evidente o pico que corresponde a um estiramento axial de $\mathrm{C}-\mathrm{OH}$; em $1076 \mathrm{~cm}^{-1}$ possui uma banda característica de estiramento C-O de éter. Sugere-se que as bandas que foram formadas indicam a entrada do grupo lauroil no grupo amino da quitosana.

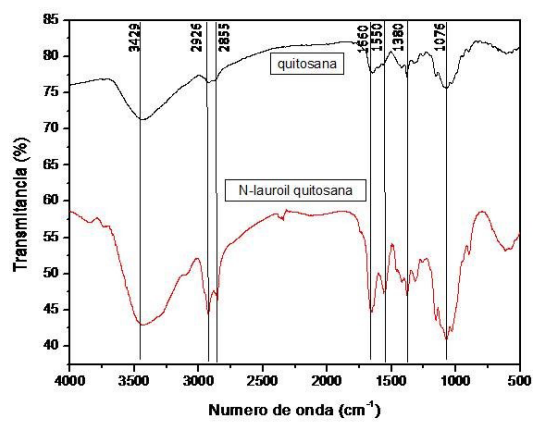

Figura 1. Espectro de Infravermelho da amostra de (a) Quitosana; (b) N-Lauroil Quitosana. 
A estabilidade térmica das amostras de quitosana e NLauroil quitosana sintetizado foram estudadas através de análise termogravimétrica. É observado que as amostras de N-lauroil quitosana e quitosana, tiveram comportamento térmico semelhante (Figura 2).

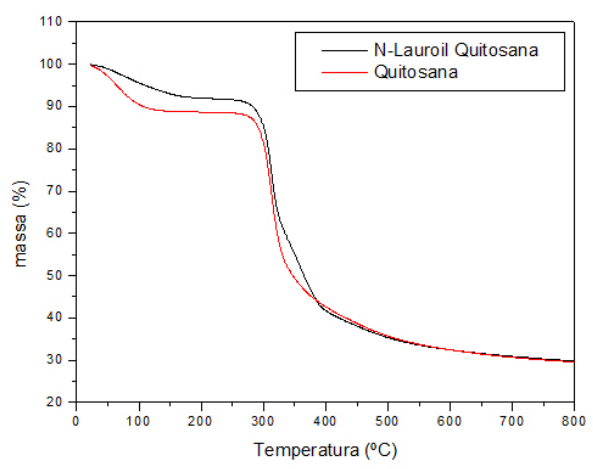

Figura 2. Curvas Termogravimétricas de Quitosana e N-Lauroil Quitosana

Observa-se que a degradação térmica da quitosana e do N-Lauroil Quitosana ocorreram em duas etapas e em temperaturas semelhantes. A primeira degradação ocorreu na faixa de temperatura de $50^{\circ}$ a $250^{\circ} \mathrm{C}$, referente a perda de água e a segunda na faixa de temperatura em torno de $300^{\circ}$ a $400^{\circ} \mathrm{C}$, referente a degradação da cadeia polimérica.

\section{Conclusões}

Através da análise dos espectros de infravermelho da quitosana e N-Lauroil quitosana, foi averiguado que houve interação dos grupos alifáticos presentes no cloreto de lauroíla com os grupos aminos $\left(-\mathrm{NH}_{2}\right)$ presentes na cadeia da quitosana.

Mesmo com a mudança na estrutura molecular da quitosana ao formar N-Lauroil Quitosana, não houve grandes alterações em seu comportamento térmico, como observado na curva Termogravimétrica.

\section{Agradecimentos \\ UEG (bolsa IC e PROBIP), CAPES e CNPq.}

\section{Referências Bibliográficas}

1. RINAUDO, M. Chitin and chitosan: properties and applications. Progress in Polymer Science, v.31. p.603-632, 2006.

2. ROBERTS, G. Chitin Chemistry. London, Macmillan, 1992. 349p.

3. VIEIRA, C.L. Adsorção de íons de cobre(II) e de íons de chumbo(II) em N-lauroil quitosana: cinética, isotermas de adsorção e parâmetros termodinâmicos. Anápolis: UEG. 135f. Dissertação, Campus de Anápolis de Ciências Exatas e Tecnologicas, Universidade Estadual de Goiais, 2016.

\section{Danillo Alencar e Silva, Aline Fernandes Barcelos, Camilla Lourenço Vieira \& Roberta Signini*}

Universidade Estadual de Goiás, Campus de Ciências Exatas e Tecnológicas Henrique Santilho. Br 153 n 3.105, Fazenda Barreiro do Meio. CEP: 75.132-903

*E-mail: roberta.signini@gmail.com 